\title{
Adiponectin is partially associated with exosomes in mouse serum
}

Worrawalan Phoonsawat ${ }^{\mathrm{a}}$, Ayako Aoki-Yoshida ${ }^{\mathrm{b}}$, Takeshi Tsuruta ${ }^{\mathrm{b}}$ and Kei Sonoyama ${ }^{\mathrm{b} *}$

${ }^{a}$ Graduate School of Agriculture, and ${ }^{b}$ Research Faculty of Agriculture, Hokkaido University, Sapporo 060-8589, Japan

Word count: 4,578

No. of Tables: 3

No. of Figures: 3

* Corresponding author:

Kei Sonoyama, Ph.D.

E-mail: ksnym@chem.agr.hokudai.ac.jp

Tel \& Fax: +81-11-706-2496

Laboratory of Food Biochemistry

Research Faculty of Agriculture

Hokkaido University

Kita-9 Nishi-9, Kita-ku, Sapporo 060-8589, Japan 


\begin{abstract}
Exosomes are membrane vesicles $30-120 \mathrm{~nm}$ in diameter that are released by many cell types and carry a cargo of proteins, lipids, mRNA, and microRNA. Cultured adipocytes reportedly release exosomes that may play a role in cell-to-cell communication during the development of metabolic diseases. However, the characteristics and function of exosomes released from adipocytes in vivo remain to be elucidated. Clearly, adipocyte-derived exosomes could exist in the circulation and may be associated with adipocyte-specific proteins such as adipocytokines. We isolated exosomes from serum of mice by differential centrifugation and analyzed adiponectin, leptin, and resistin in the exosome fraction. Western blotting detected adiponectin but no leptin and only trace amounts of resistin in the exosome fraction. The adiponectin signal in the exosome fraction was decreased by proteinase $\mathrm{K}$ treatment and completely quenched by a combination of proteinase K and Triton X-100. Quantitative ELISA showed that the exosome fraction contains considerable amounts of adiponectin, but not leptin or resistin. The concentration of adiponectin in the serum and the ratio of adiponectin to total protein in the exosome fraction were lower in obese mice than in lean mice. These results suggest that a portion of adiponectin exists as a transmembrane protein in the exosomes in mouse serum. We propose adiponectin as a marker of exosomes released from adipocytes in vivo.
\end{abstract}

Keywords: Exosome; Adiponectin; Leptin; Resistin; Mice 


\section{Introduction}

Exosomes are membrane vesicles with a size of 30-120 nm that are released by many different cell types under physiological and pathological conditions [1]. They have been found in many biological fluids including blood, bronchoalveolar lavage fluid, urine, bile, and breast milk [1]. Exosomes harbor a wide variety of proteins, lipids, mRNA, and microRNA, which can be transferred to another cell, and are implicated in intercellular communication by transferring molecules [2-4]. Indeed, there is increasing evidence that exosomes play an important role in normal physiological processes, development, viral infections and other human diseases [5-8]. In addition, recent studies have highlighted important applications of exosomes as a source of disease biomarkers $[4,9,10]$ and as drug delivery vehicles $[11,12]$. Thus, exosomes have gained much attention, both with regard to their physiological and pathological functions and more practical applications.

Previous studies have identified exosomes in the culture supernatant of mouse adipose tissue [13], rat primary adipocytes [14-16], and mouse adipocyte cell line 3T3-L1 [17]. Deng et al. isolated exosomes from the culture supernatant of visceral adipose tissue excised from mice and showed that injection of the exosomes derived from diet-induced or genetically (leptin-deficient $o b / o b$ ) obese mice into wild-type lean mice results in macrophage activation and insulin resistance [13]. Müller et al. found that rat primary adipocytes release exosomes, which may transfer lipogenic and/or lipolytic information between large and small adipocytes [14-16]. More recently, Sano et al. isolated exosomes from the culture supernatant of differentiated 3T3-L1 cells and demonstrated that exosomes isolated from cells cultured under hypoxic conditions are enriched in enzymes related to lipogenesis and promote lipid accumulation in recipient 3T3-L1 adipocytes [17]. These findings suggest that adipocyte-derived exosomes play a role in cell-to-cell communication during the development of metabolic diseases. However, the characteristics and function of exosomes released from adipocytes in vivo remain to be elucidated. 
Clearly, exosomes released from adipocytes could exist in the circulation. In addition, because the composition of exosomes is heterogenic, depending on the cellular origin of the exosome, adipocyte-derived exosomes could be accompanied by molecules produced specifically in adipocytes. In this context, we postulated that such molecules associated with exosomes in the serum could be markers for adipocyte-derived exosomes in vivo. In the present study, we particularly focused on secretory proteins produced specifically in adipocytes, namely adipocytokines including adiponectin, leptin, and resistin.

\section{Materials and methods}

\section{1. Animal care}

All study protocols were approved by the Animal Use Committee of Hokkaido University (approval no. 08-0139). Animals were maintained in accordance with the Hokkaido University guidelines for the care and use of laboratory animals. Male C57BL/6J JmsSlc (B6), C57BL/6J HamSlc-+/+ (+/+), and C57BL/6J HamSlc-ob/ob (ob/ob) mice (age, 5 weeks) were purchased from Japan SLC and housed in standard plastic cages in a temperature-controlled $\left(23 \pm 2{ }^{\circ} \mathrm{C}\right)$ room under a 12-hr light-dark cycle. They were allowed free access to water and standard chow diet (MR stock; Nosan Corporation) for 2 weeks. In a separate experiment, male B6 mice (age, 5 weeks) were fed either normal-fat diet (NFD) (D12450B; 11.1\%kcal from fat, Research Diets) or high-fat diet (HFD) (D12492; 62.7\%kcal from fat, Research Diets) for 4 months.

\section{2. Exosome isolation}

Mice were deprived of food overnight, and total blood was obtained from the carotid artery under diethyl ether anesthesia. Exosomes were isolated by differential centrifugation according to Théry et al [18]. The post-ultracentrifuge pellet was suspended in the same volume of PBS as the original serum samples. This suspension was referred to as the exosome fraction. The protein concentration in the serum and exosome fraction was determined by a BCA protein assay (Thermo Scientific) according to the manufacturer's instructions. Samples were stored at $-80^{\circ} \mathrm{C}$ until use. 


\subsection{Treatment of exosomes with proteinase $K$}

The exosome fraction was treated with either $30 \mu \mathrm{g} / \mathrm{mL}$ proteinase $\mathrm{K}, 0.5 \%$ Triton $\mathrm{X}-100$, or a combination of both proteinase $\mathrm{K}$ and Triton $\mathrm{X}-100$ at $37^{\circ} \mathrm{C}$ for 5 , 15 , or $30 \mathrm{~min}$, after which $3 \mathrm{x}$ SDS-PAGE loading buffer composed of 195 mM Tris-HCl, pH 6.8, 10\% (w/v) SDS, 30\% (w/v) glycerol, $15 \%$ (v/v) $\beta$-mercaptoethanol, and $0.01 \%$ (w/v) bromophenol blue was added. After boiling for $3 \mathrm{~min}$, the samples were western blotted.

\subsection{Discontinuous OptiPrep gradient ultracentrifugation}

Exosomes were further separated by discontinuous OptiPrep gradient ultracentrifugation according to Mathivanan et al [19] with slight modification. In brief, the exosome fraction (500 $\mu \mathrm{L}$ ) was overlaid on a discontinuous OptiPrep-sucrose gradient (50, 25, 12.5, and 6\% iodixanol concentration from OptiPrep solution (Axis-Shield) in $0.25 \mathrm{M}$ sucrose, $10 \mathrm{mM}$ Tris-HCl, pH 7.4) and ultracentrifuged for $18 \mathrm{hr}$ at $100,000 \mathrm{x} \mathrm{g}, 4^{\circ} \mathrm{C}$ in a Beckman SW40Ti rotor. Fractions (1 $\mathrm{mL}$ ) were collected from the top of the gradient and diluted with $2 \mathrm{~mL} 20 \mathrm{mM}$ Tris-HCl, pH 7.4, followed by ultracentrifugation for $3 \mathrm{hr}$ at $100,000 \mathrm{x} \mathrm{g}, 4^{\circ} \mathrm{C}$. The pellet in each fraction was resuspended in $100 \mu \mathrm{L}$ PBS and then western blotted. The density of each fraction was determined by absorbance at $340 \mathrm{~nm}$ using a duplicate parallel discontinuous OptiPrep gradient overlaid with $0.25 \mathrm{M}$ sucrose, $10 \mathrm{mM}$ Tris, $\mathrm{pH} 7.4$, according to the manufacturer's application sheet (Axis-Shield). The absorbance was measured using a Synergy Mx 96-well microplate reader (BioTek Instruments).

\subsection{Western blot analysis}

Samples were separated by SDS-PAGE under reducing and nonreducing conditions. For reducing conditions, samples were added to 3x SDS-PAGE loading buffer, described above, and then boiled for 3 min. For nonreducing conditions, $\beta$-mercaptoethanol was excluded from the loading buffer, and the samples were not boiled. Electrophoresed proteins were electrophoretically transferred to Hybond C extra nitrocellulose membrane (Amersham 
International). Membranes were then probed with mouse anti-adiponectin (Enzo Life Sciences), rat anti-CD63 (BioLegend), rabbit anti-leptin (BioVendor), and rat anti-resistin (Enzo Life Sciences) overnight at $4^{\circ} \mathrm{C}$. Membranes were then incubated with horseradish peroxidase-conjugated secondary antibodies for $1 \mathrm{hr}$ at RT. The blots were visualized by ECL chemiluminescence (GE Healthcare) according to the manufacturer's instructions.

\subsection{ELISA}

The concentration of adiponectin, leptin, and resistin in serum and exosome fraction was determined using ELISA kits (Mouse Adiponectin/Acrp30 DuoSet, R\&D Systems; Mouse Leptin ELISA Kit, Morinaga Institute of Biological Science; Mouse Resistin Quantikine ELISA Kit, R\&D Systems) according to the manufacturers’ instructions.

\subsection{Statistical analysis}

Results are presented as means \pm SEM. Student's $t$-test was used to compare mean values. Data analysis was performed using GraphPad Prism for Macintosh (version 6; GraphPad Software). $P$ values of $<0.05$ were considered to be statistically significant.

\section{Results}

\subsection{Serum adiponectin is partially associated with exosomes}

When samples containing the same amount of protein in the serum, exosome fraction, and supernatant from the initial ultracentrifugation of serum were separated by SDS-PAGE and western blotted with a probe to an antibody against CD63, a typical marker protein of exosomes [1], the probe signal was observed in all three samples, and the intensity was higher in the exosome fraction than in the serum or supernatant (Fig. 1A). Next, we separated samples having the same volume of serum, exosome fraction, and supernatant. On western blotting with anti-adiponectin antibody, a probe signal was observed in all three fractions, with a lower intensity in the exosome fraction (Fig. 1B). In addition, a leptin probe signal was observed in the serum and supernatant, but not the exosome fraction. Furthermore, a resistin probe signal 
was observed in the serum and supernatant, but only a faint signal was detected in the exosome fraction. Although the signal intensity for both CD63 and adiponectin was unchanged by Triton X-100 treatment, proteinase K treatment quenched the CD63 signal (Fig. 2A). Similarly, the signal intensity for adiponectin was lowered by proteinase K treatment, though a faint signal remained. However, the combination of proteinase K and Triton X-100 completely quenched the adiponectin signal. On western blots of fractions from the ultracentrifugation on a discontinuous gradient, signals for adiponectin and CD63 were detected at a density of 1.17 g/mL (fraction 10)(Fig. 2B). In addition, weaker signals for adiponectin and CD63 were also observed at a density of 1.07-1.08 g/mL (fractions 4 and 5).

\subsection{High-molecular weight adiponectins are associated with exosomes}

Adiponectin exists in the circulation as multimeric complexes including a low-molecular-weight (LMW, 67 kDa), middle-molecular-weight (MMW, 136 kDa) and high-molecular-weight (HMW, >300 kDa) forms [20, 21]. When samples were separated by SDS-PAGE under nonreducing conditions followed by western blotting, the MMW form was predominant in the serum and supernatant, whereas the HMW form was predominant in the exosome fraction (Fig. 3).

\subsection{Adiponectin is decreased in the serum and exosomes in obese mice}

Although leptin was not detected in the exosome fraction by ELISA, the concentration of adiponectin and resistin in the exosome fraction was $154 \pm 28$ and $0.36 \pm 0.05 \mathrm{ng} / \mathrm{mL}$, which respectively account for $4.4 \pm 1.0$ and $0.9 \pm 0.1 \%$ of the proteins in the serum (Table 1 ). Compared to $+/+$ lean mice, the serum concentration of total protein in genetically obese $\mathrm{ob} / \mathrm{ob}$ mice was higher, while the serum concentration of adiponectin was lower (Table 2). Similarly, total protein concentration in the exosome fraction was higher in $o b / o b$ mice than in $+/+$ mice. In contrast, there were no differences in adiponectin concentration in the exosome fraction between the two groups. In the exosome fraction, the ratio of adiponectin to total protein was significantly lower in $o b / o b$ mice $(0.0157 \pm 0.0031 \%)$ than in $+/+$ mice $(0.0315 \pm 0.0018 \%)$. 
The concentration of adiponectin in the exosome fraction in $+/+$ and $o b / o b$ mice accounts respectively for $1.9 \pm 0.4$ and $2.1 \pm 0.5 \%$ of the adiponectin in the serum. In addition, HFD-fed obese mice had a lower serum concentration of adiponectin than NFD-fed lean mice, whereas total protein concentration in the serum was the same for the two groups (Table 3). In the exosome fraction, there were no differences in either total protein or adiponectin concentration between the groups, while the ratio of adiponectin to total protein was significantly lower in HFD-fed obese mice $(0.0515 \pm 0.0098 \%)$ than in NFD-fed lean mice $(0.0766 \pm 0.0062 \%)$. The concentration of adiponectin in the exosome fraction in NFD-fed and HFD-fed mice accounted respectively for $11.3 \pm 1.3$ and $10.9 \pm 2.2 \%$ of adiponectin in the serum.

\section{Discussion}

Based on western blotting, CD63, a well-known protein marker of exosomes [1], was concentrated in the pellet of mouse serum after ultracentrifugation, suggesting successful isolation of exosomes. In the exosome fraction, we detected adiponectin and trace amounts of resistin, but not leptin. In addition, after ultracentrifugation on a discontinuous gradient, both adiponectin and CD63 were detected in a fraction at a density of $1.17 \mathrm{~g} / \mathrm{mL}$, consistent with the density of exosomes [1]. Thus, it seems likely that a portion of the adiponectin is associated with exosomes in mouse serum. In fact, previous in vitro studies have demonstrated that mouse exosomes are associated with adiponectin. Deng et al. and Sano et al. respectively identified adiponectin by proteomic analysis in the exosomes released from cultured mouse adipose tissue and mouse adipocyte cell line 3T3-L1 [13, 17]. Given that adiponectin is produced exclusively by adipocytes, and considering that cultured adipose tissue and 3T3-L1 adipocytes release exosomes $[13,17]$, it is possible that adiponectin-associated exosomes in serum are derived from adipocytes. In other words, adiponectin could be a marker for adipocyte-derived exosomes in the circulation.

Our western blot analysis showed that the signal intensity for CD63 in the exosome fraction was decreased by treatment with proteinase $\mathrm{K}$, suggesting that CD63 is not an intrinsic protein 
but rather a transmembrane protein, which is consistent with previous reports [1]. Along with CD63, adiponectin was sensitive to proteinase $\mathrm{K}$ treatment. A weak adiponectin signal remained after a 30 min treatment with proteinase $\mathrm{K}$, whereas the combination of both proteinase K and Triton X-100 completely quenched the signal. These results suggest that adiponectin exists as a transmembrane protein in the serum exosomes and that the anti-adiponectin antibody we used may recognize the transmembrane or intraexosomal domain of adiponectin. Thus, it may be possible to analyze and isolate adipocyte-derived exosomes by immunomagnetic beads using anti-adiponectin antibodies that recognize the extraexosomal domain of adiponectin.

Quantitative analysis by ELISA showed that the amount of adiponectin in the exosome fraction accounts for approximately $2-10 \%$ of total adiponectin in the serum. The physiological implications of partial association of serum adiponectin with exosomes remain to be clarified. Adiponectin exerts its physiological function via the transmembrane receptors AdipoR1 and AdipoR2 [22]. AdipoR1 is a high-affinity receptor in the globular domain of adiponectin and is primarily expressed in skeletal muscle, whereas AdipoR2 has an intermediate affinity for the collagenous and globular domains of adiponectin and is abundant in the liver [22]. Association of adiponectin with exosomes may influence the recognition of the collagenous, globular, or both domains of adiponectin by the receptors, thereby affecting its physiological function. Precise analysis of the structural aspects of adiponectin associated with exosomes would provide relevant information.

Serum concentration of adiponectin is reportedly decreased in obese human and rodent models $[23,24]$. We observed a lower concentration of serum adiponectin in $o b / o b$ mice and HFD-fed obese mice when compared to lean mice. In addition, adiponectin knockout mice exhibit insulin resistance and diabetes [25]. Furthermore, administration of adiponectin reportedly lowers blood glucose levels, ameliorates insulin resistance [26, 27] and increases fatty acid oxidation [28]. Thus, adiponectin protects against metabolic syndrome. Adiponectin exists as LMW, 
MMW and HMW forms in the circulation [20, 21], and HMW adiponectins have a more relevant role in insulin sensitivity and in protecting metabolic diseases $[21,29,30]$. In the present study, western blotting following SDS-PAGE under nonreducing and unheated conditions indicated that, although MMW adiponectins are the predominant form in the serum, HMW adiponectins are present principally in the exosome fraction. These findings suggest that exosome-associated adiponectin and exosome-free adiponectin may have different physiological and pathological functions in vivo. It would be of interest to test whether the administration of exosome-associated adiponectin and exosome-free adiponectin exert different effects, particularly in terms of insulin-sensitizing and anti-inflammatory functions, on recipient animals.

Because exosomes seem to reflect the diverse functional and dysfunctional states of the releasing cells, adipocyte-derived exosomes in the circulation could be influenced qualitatively and quantitatively by obesity. In fact, the total amount of exosomal proteins in the serum is reportedly higher in ob/ob mice than in wild-type mice [17]. Similarly, we observed that the protein concentration in the exosome fraction was higher in $o b / o b$ mice than in $+/+$ mice, although there were no differences between HFD-fed obese and NFD-fed lean mice. In addition, cultured adipose tissue of $o b / o b$ mice and diet-induced obese mice released more exosomal proteins than wild-type lean mice [13]. Thus, it appears likely that obesity increases the release of exosomal proteins from adipose tissue, although the mechanism behind this release and the physiological implications remain unknown. We also observed that obesity decreased the ratio of adiponectin to total protein in the exosome fraction. Because adiponectin expression is reduced in obese adipocytes [23], we presume that the lower concentration of adiponectin in serum exosomes may reflect reduced production of adiponectin in obese adipocytes.

Taken together, the present study showed that serum adiponectin is partially associated with exosomes in mice. Considering that adiponectin is produced exclusively by adipocytes, adiponectin-associated exosomes in serum could be derived from adipocytes. Further studies 
are needed to clarify the physiological implications for the partial association of serum adiponectin with exosomes. Nevertheless, we propose that adiponectin could be a marker for exosomes released from adipocytes in vivo.

\section{Acknowledgments}

This study was supported in part by a Grant-in-Aid for Scientific Research from The Ministry of Education, Science, Sports and Culture of Japan (no. 23380069), by the Regional Innovation Strategy Support Program of the MEXT, and by the Mishima Kaiun Memorial Foundation.

\section{References}

1. A.V. Vlassov, S. Magdaleno, R. Setterquist, R. Conrad, Exosomes: current knowledge of their composition, biological functions, and diagnostic and therapeutic potentials. Biochim. Biophys. Acta. 1820 (2012) 940-948.

2. R.M. Johnstone, M. Adam, J.R. Hammond, L. Orr, C. Turbide, Vesicle formation during reticulocyte maturation. Association of plasma membrane activities with released vesicles (exosomes). J. Biol. Chem. 262 (1987) 9412-9420.

3. H. Valadi, K. Ekström, A. Bossios, M. Sjöstrand, J.J. Lee, J.O. Lötvall, Exosome-mediated transfer of mRNAs and microRNAs is a novel mechanism of genetic exchange between cells. Nat. Cell Biol. 9 (2007) 654-659.

4. J. Skog, T. Würdinger, S. van Rijn, D.H. Meijer, L. Gainche, M. Sena-Esteves, W.T. Curry, Jr, B.S. Carter, A.M. Krichevsky, X.O. Breakefield, Glioblastoma microvesicles transport RNA and proteins that promote tumour growth and provide diagnostic biomarkers. Nat. Cell Biol. 10 (2008) 1470-1476.

5. A.J. Abusamra, Z. Zhong, X. Zheng, M. Li, T.E. Ichim, J.L. Chin, W.P. Min, Tumor exosomes expressing Fas ligand mediate CD8 ${ }^{+}$T-cell apoptosis. Blood Cells Mol. Dis. 35 (2005) 169-173.

6. M. Fabbri, A. Paone, F. Calore, R. Galli, E. Gaudio, R. Santhanam, F. Lovat, P. Fadda, C. Mao, G.J. Nuovo, N. Zanesi, M. Crawford, G.H. Ozer, D. Wernicke, H. Alder, M.A. 
Caligiuri, P. Nana-Sinkam, D. Perrotti, C.M. Croce, MicroRNAs bind to Toll-like receptors to induce prometastatic inflammatory response. Proc. Natl. Acad. Sci. U. S. A. 109 (2012) E2110-E2116.

7. D.M. Pegtel, K. Cosmopoulos, D.A. Thorley-Lawson, M.A. van Eijndhoven, E.S. Hopmans, J.L. Lindenberg, T.D. de Gruijl, T. Würdinger, J.M. Middeldorp, Functional delivery of viral miRNAs via exosomes. Proc. Natl. Acad. Sci. U. S. A. 107 (2010) 6328-6333.

8. E. Segura, C. Nicco, B. Lombard, P. Véron, G. Raposo, F. Batteux, S. Amigorena, C. Théry, ICAM-1 on exosomes from mature dendritic cells is critical for efficient naive T-cell priming. Blood. 106 (2005) 216-223.

9. E. Hosseini-Beheshti, S. Pham, H. Adomat, N. Li, E.S. Tomlinson Guns, Exosomes as biomarker enriched microvesicles: characterization of exosomal proteins derived from a panel of prostate cell lines with distinct AR phenotypes. Mol. Cell. Proteomics. 11 (2012) 863-885.

10. S. Saman, W. Kim, M. Raya, Y. Visnick, S. Miro, S. Saman, B. Jackson, A.C. McKee, V.E. Alvarez, N.C. Lee, G.F. Hall, Exosome-associated tau is secreted in tauopathy models and is selectively phosphorylated in cerebrospinal fluid in early Alzheimer disease. J. Biol. Chem. 287 (2012) 3842-3849.

11. L. Alvarez-Erviti, Y. Seow, H. Yin, C. Betts, S. Lakhal, M.J. Wood, Delivery of siRNA to the mouse brain by systemic injection of targeted exosomes. Nat. Biotechnol. 29 (2011) 341-345.

12. S. El Andaloussi, S. Lakhal, I. Mäger, M.J. Wood, Exosomes for targeted siRNA delivery across biological barriers. Adv. Drug Deliv. Rev. 65 (2013) 391-397.

13. Z.B. Deng, A. Poliakov, R.W. Hardy, R. Clements, C. Liu, Y. Liu, J. Wang, X. Xiang, S. Zhang, X. Zhuang, S.V. Shah, D. Sun, S. Michalek, W.E. Grizzle, T. Garvey, J. Mobley, H.G. Zhang, Adipose tissue exosome-like vesicles mediate activation of macrophage-induced insulin resistance. Diabetes. 58 (2009) 2498-2505.

14. G. Müller, C. Jung, J. Straub, S. Wied, W. Kramer, Induced release of membrane vesicles 
from rat adipocytes containing glycosylphosphatidylinositol-anchored microdomain and lipid droplet signalling proteins. Cell Signal. 21 (2009) 324-338.

15. G. Müller, C. Jung, S. Wied, G. Biemer-Daub, Induced translocation of glycosylphosphatidylinositol-anchored proteins from lipid droplets to adiposomes in rat adipocytes. Br. J. Pharmacol. 158 (2009) 749-770.

16. G. Müller, M. Schneider, G. Biemer-Daub, S. Wied, Microvesicles released from rat adipocytes and harboring glycosylphosphatidylinositol-anchored proteins transfer RNA stimulating lipid synthesis. Cell Signal. 23 (2011) 1207-1223.

17. S. Sano, Y. Izumi, T. Yamaguchi, T. Yamazaki, M. Tanaka, M. Shiota, M. Osada-Oka, Y. Nakamura, M. Wei, H. Wanibuchi, H. Iwao, M. Yoshiyama, Lipid synthesis is promoted by hypoxic adipocyte-derived exosomes in 3T3-L1 cells. Biochem. Biophys. Res. Commun. 445 (2014) 327-333.

18. C. Théry, S. Amigorena, G. Raposo, A. Clayton, Isolation and characterization of exosomes from cell culture supernatants and biological fluids. Curr. Protoc. Cell Biol. Chapter 3 (2006) Unit 3.22.

19. S. Mathivanan, J.W. Lim, B.J. Tauro, H. Ji, R.L. Moritz, R.J. Simpson, Proteomics analysis of A33 immunoaffinity-purified exosomes released from the human colon tumor cell line LIM1215 reveals a tissue-specific protein signature. Mol. Cell. Proteomics. 9 (2010) 197-208.

20. U.B. Pajvani, X. Du, T.P. Combs, A.H. Berg, M.W. Rajala, T. Schulthess, J. Engel, M. Brownlee, P.E. Scherer, Structure-function studies of the adipocyte-secreted hormone Acrp30/adiponectin. Implications fpr metabolic regulation and bioactivity. J. Biol. Chem. 278 (2003) 9073-9085.

21. H. Waki, T. Yamauchi, J. Kamon, Y. Ito, S. Uchida, S. Kita, K. Hara, Y. Hada, F. Vasseur, P. Froguel, S. Kimura, R. Nagai, T. Kadowaki, Impaired multimerization of human adiponectin mutants associated with diabetes. Molecular structure and multimer formation of adiponectin. J. Biol. Chem. 278 (2003) 40352-40363.

22. T. Yamauchi, T. Kadowaki, Adiponectin receptor as a key player in healthy longevity and 
obesity-related diseases. Cell Metab. 17 (2013) 185-96.

23. Y. Arita, S. Kihara, N. Ouchi, M. Takahashi, K. Maeda, J. Miyagawa, K. Hotta, I. Shimomura, T. Nakamura, K. Miyaoka, H. Kuriyama, M. Nishida, S. Yamashita, K. Okubo, K. Matsubara, M. Muraguchi, Y. Ohmoto, T. Funahashi, Y. Matsuzawa, Paradoxical decrease of an adipose-specific protein, adiponectin, in obesity. Biochem. Biophys. Res. Commun. 257 (1999) 79-83.

24. E. Hu, P. Liang, B.M. Spiegelman, AdipoQ is a novel adipose-specific gene dysregulated in obesity. J. Biol. Chem. 271 (1996) 10697-10703.

25. N. Kubota, Y. Terauchi, T. Yamauchi, T. Kubota, M. Moroi, J. Matsui, K. Eto, T. Yamashita, J. Kamon, H. Satoh, W. Yano, P. Froguel, R. Nagai, S. Kimura, T. Kadowaki, T. Noda, Disruption of adiponectin causes insulin resistance and neointimal formation. J. Biol. Chem. 277 (2002) 25863-25866.

26. A.H. Berg, T.P. Combs, X. Du, M. Brownlee, P.E. Scherer, The adipocyte-secreted protein Acrp30 enhances hepatic insulin action. Nat. Med. 7 (2001) 947-953.

27. T. Yamauchi, J. Kamon, H. Waki, Y. Terauchi, N. Kubota, K. Hara, Y. Mori, T. Ide, K. Murakami, N. Tsuboyama-Kasaoka, O. Ezaki, Y. Akanuma, O. Gavrilova, C. Vinson, M.L. Reitman, H. Kagechika, K. Shudo, M. Yoda, Y. Nakano, K. Tobe, R. Nagai, S. Kimura, M. Tomita, P. Froguel, T. Kadowaki, The fat-derived hormone adiponectin reverses insulin resistance associated with both lipoatrophy and obesity. Nat. Med. 7 (2001) 941-946.

28. T. Yamauchi, J. Kamon, Y. Minokoshi, Y. Ito, H. Waki, S. Uchida, S. Yamashita, M. Noda, S. Kita, K. Ueki, K. Eto, Y. Akanuma, P. Froguel, F. Foufelle, P. Ferre, D. Carling, S. Kimura, R. Nagai, B.B. Kahn, T. Kadowaki, Adiponectin stimulates glucose utilization and fatty-acid oxidation by activating AMP-activated protein kinase. Nat. Med. 8 (2002) 1288-1295.

29. U.B. Pajvani, M. Hawkins, T.P. Combs, M.W. Rajala, T. Doebber, J.P. Berger, J.A. Wagner, M. Wu, A. Knopps, A.H. Xiang, K.M. Utzschneider, S.E. Kahn, J.M. Olefsky, T.A. Buchanan, P.E. Scherer, Complex distribution, not absolute amount of adiponectin, correlates with thiazolidinedione-mediated improvement in insulin sensitivity. J. Biol. 
Chem. 279 (2004) 12152-12162.

30. C. Lara-Castro, N. Luo, P. Wallace, R.L. Klein, W.T. Garvey, Adiponectin multimeric complexes and the metabolic syndrome trait cluster. Diabetes. 55 (2006) 249-259. 
Table 1 Concentration of total protein and adipocytokines in serum and exosome fraction of B6 mice.

\begin{tabular}{lcc}
\hline & Serum & Exosome fraction \\
\hline Total protein $(\mathrm{mg} / \mathrm{mL})$ & $48.1 \pm 0.8$ & $0.47 \pm 0.06$ \\
Adiponectin $(\mathrm{ng} / \mathrm{mL})$ & $3745 \pm 241$ & $154 \pm 28$ \\
Leptin $(\mathrm{ng} / \mathrm{mL})$ & $5.89 \pm 0.12$ & not detectable \\
Resistin $(\mathrm{ng} / \mathrm{mL})$ & $39.73 \pm 1.55$ & $0.36 \pm 0.05$ \\
\hline
\end{tabular}

${ }^{1}$ The exosome fraction was prepared by suspending the pellet after ultracentrifugation in the same volume of PBS as the original serum sample. Values are expressed as means with SEM. 
Table 2 Body weight and concentration of total protein and adipocytokines in serum and exosome fraction of $+/+$ and $o b / o b$ mice.

\begin{tabular}{lcc}
\hline & $+/+$ & $o b / o b$ \\
\hline Body weight (g) & $28.5 \pm 2.0$ & $48.7 \pm 2.3^{*}$ \\
Serum & & \\
$\quad$ Total protein $(\mathrm{mg} / \mathrm{mL})$ & $51.6 \pm 0.4$ & $64.2 \pm 1.4^{*}$ \\
$\quad$ Adiponectin $(\mathrm{ng} / \mathrm{mL})$ & $7562 \pm 736$ & $5053 \pm 191^{*}$ \\
Exosome fraction & & \\
$\quad$ Total protein $(\mathrm{mg} / \mathrm{mL})$ & $0.43 \pm 0.07$ & $0.67 \pm 0.04^{*}$ \\
Adiponectin $(\mathrm{ng} / \mathrm{mL})$ & $133 \pm 21$ & $103 \pm 19$ \\
\hline
\end{tabular}

${ }^{1}$ The exosome fraction was prepared by suspending the pellet after ultracentrifugation in the same volume of PBS as the itinial serum sample. Values are expressed as means \pm SEM.

Comparison of mean values was done by Student's $t$-test. * $P<0.05$ vs. $+/+$. 
Table 3 Body weight and concentration of total protein and adipocytokines in serum and exosome fraction of B6 mice fed normal and high-fat diets.

\begin{tabular}{lcc}
\hline & Normal-fat diet & High-fat diet \\
\hline Body weight (g) & $27.8 \pm 0.8$ & $51.4 \pm 0.5^{*}$ \\
Serum & & \\
$\quad$ Total protein $(\mathrm{mg} / \mathrm{mL})$ & $43.4 \pm 1.2$ & $45.6 \pm 1.5$ \\
$\quad$ Adiponectin $(\mathrm{ng} / \mathrm{mL})$ & $5403 \pm 439$ & $4497 \pm 336^{*}$ \\
Exosome fraction & & $0.93 \pm 0.10$ \\
$\quad$ Total protein $(\mathrm{mg} / \mathrm{mL})$ & $0.84 \pm 0.16$ & $476 \pm 98$ \\
Adiponectin $(\mathrm{ng} / \mathrm{mL})$ & $609 \pm 84$ & \\
\hline
\end{tabular}

${ }^{1}$ The exosome fraction was prepared by suspending the pellet after ultracentrifugation in the same volume of PBS as the original serum sample. Values are expressed as means \pm SEM. Comparison of mean values was by Student's $t$-test. * $P<0.05$ vs. normal-fat diet. 


\section{Figure legends}

Figure 1 SDS-PAGE and western blotting of B6 mouse serum, exosome fraction, and supernatant. (A) Upper panel shows Coomassie brilliant blue staining of SDS-PAGE gels, and lower panel shows the western blot probed with antibody to CD63. Samples with the same protein concentration were applied in each lane and electrophoresed under reducing conditions. (B) Samples in which the original serum volumes were the same were applied in each lane, electrophoresed under reducing conditions, and then probed with antibodies to adiponectin, leptin, and resistin.

Figure 2 (A) Effect of proteinase $\mathrm{K}$ and Triton X-100 on adiponectin and CD63 in the exosome fraction prepared from B6 mouse serum. The exosome fraction was treated either with 30 $\mu \mathrm{g} / \mathrm{mL}$ proteinase $\mathrm{K}, 0.5 \%$ Triton $\mathrm{X}-100$, or a combination of both at $37^{\circ} \mathrm{C}$ for 5,15 , or $30 \mathrm{~min}$. Samples were electrophoresed under reducing conditions and then probed with antibodies to adiponectin and CD63. (B) Density gradient separation of exosomes prepared from B6 mouse serum. The exosome fraction was separated by ultracentrifugation on a discontinuous OptiPrep gradient and electrophoresed under reducing conditions, then probed with antibodies to adiponectin and CD63.

Figure 3 Western blotting of adiponectin under nonreducing, unheated conditions. The exosome fraction was prepared from B6 mouse serum, and samples with the same adiponectin concentration were applied in each lane and probed with anti-adiponectin antibody. 


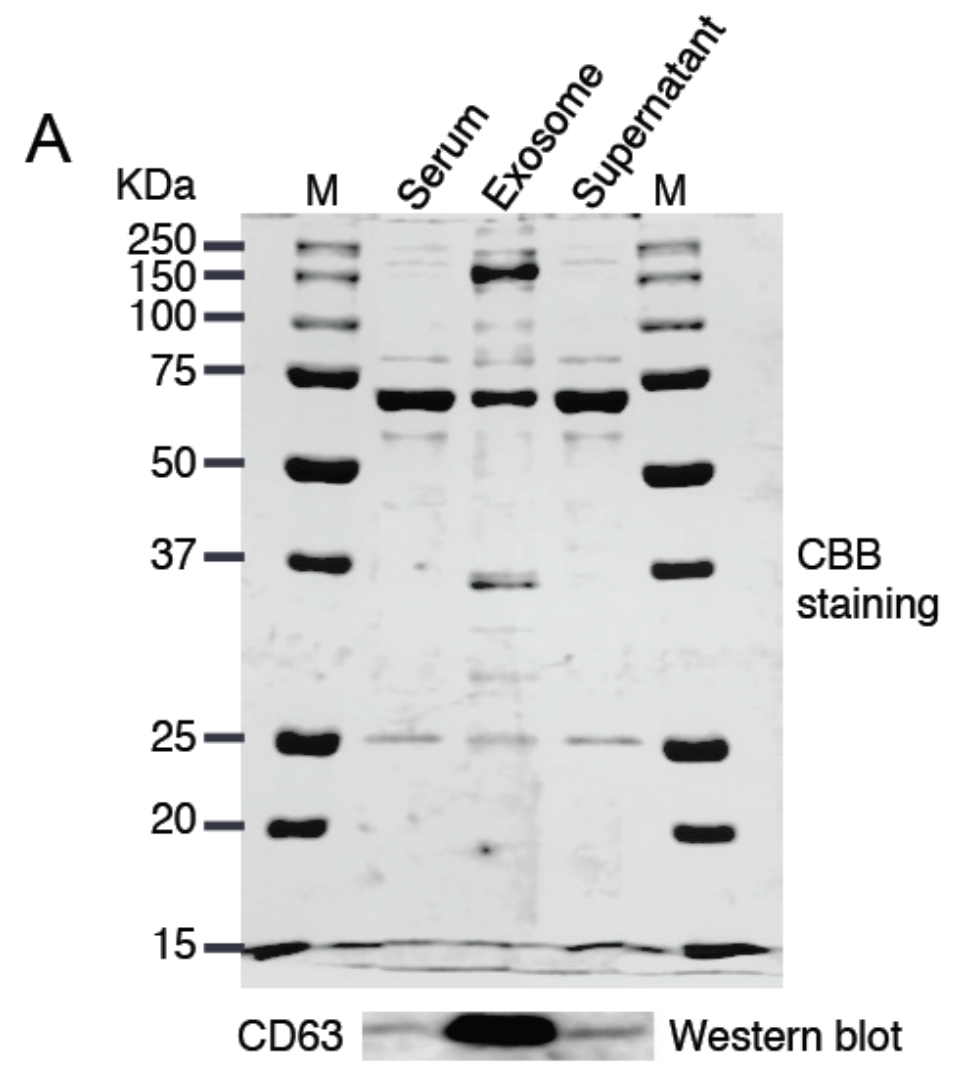

B

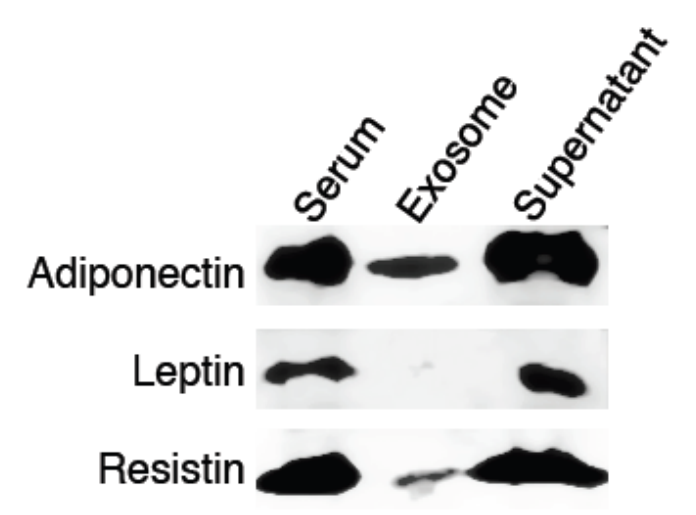

Fig. 1 Phoonsawat et al. 


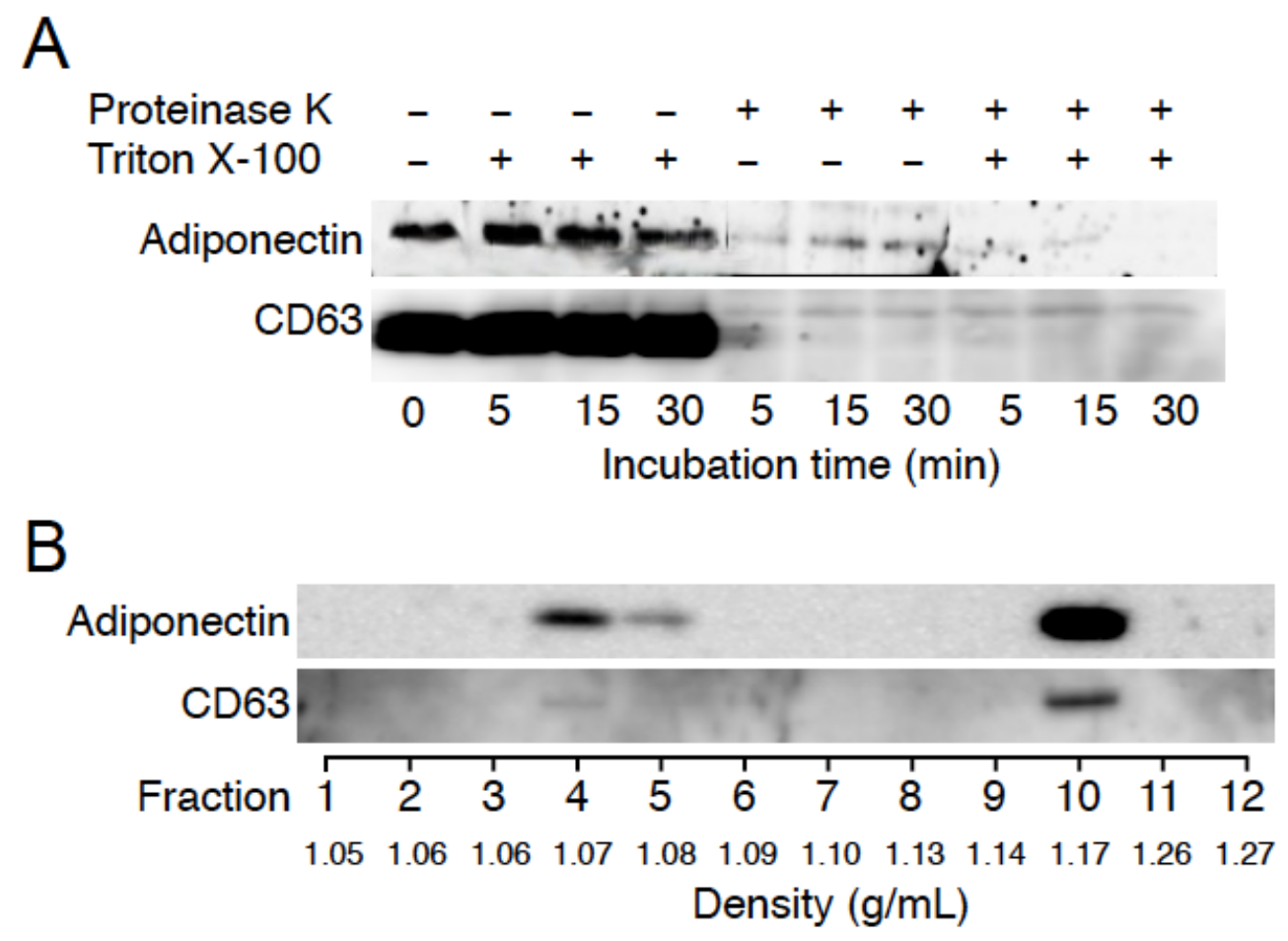

Fig. 2 Phoonsawat et al. 


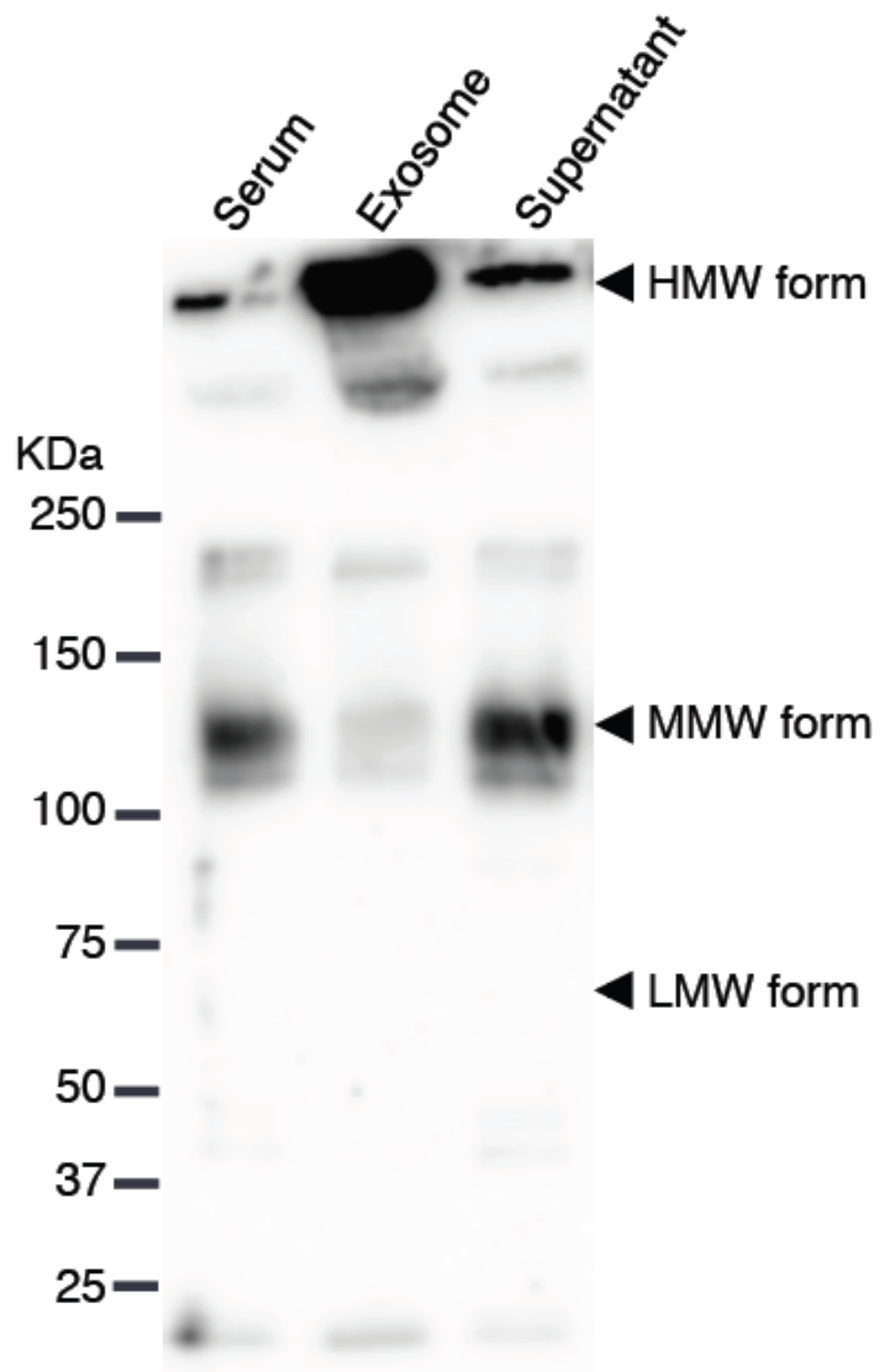

Fig. 3 Phoonsawat et al. 